

\section{EXPEDIENTE}

Universidade do Estado do Rio de Janeiro - UERJ

Instituto de Estudos Sociais e Políticos - IESP

\section{CADERNOS DE ESTUDOS SOCIAIS E POLÍTICOS}

www.e-publicacoes.uerj.br/index.php/CESP

\section{COMITÊ EDITORIAL}

Giovana Esther Zucatto, IESP-UERJ

Helio Cannone, IESP-UERJ

Marcelo Borel, IESP-UERJ

Marcia Rangel Candido, IESP-UERJ

Marina Rute Pacheco, IESP-UERJ

Mariane Silva Reghim, IESP-UERJ

Paulo Joaquim Da Silva Rodrigues, IESP-UERJ

Raul Nunes de Oliveira, IESP-UERJ

\section{CAPA, LAYOUT E DIAGRAMAÇÃO}

Marcia Rangel Candido

Raul Nunes de Oliveira

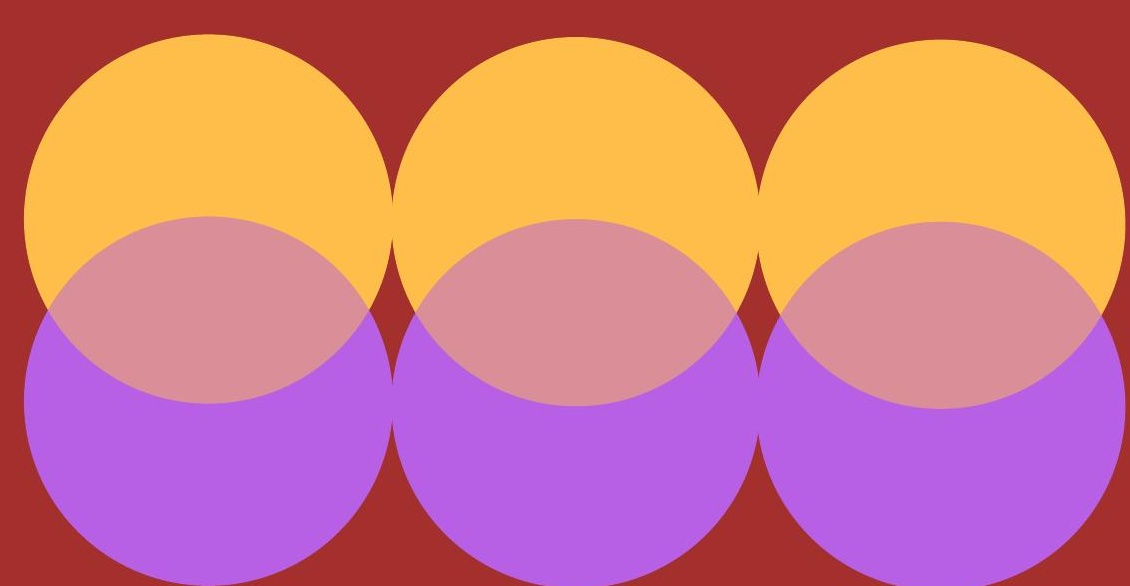


Apresentação

Mariane Silva Reghim e Marcelo Borel

Dossiê

As Expressões Do Racismo Institucional Nas Universidades Federais Do

Estado Do Rio De Janeiro: Mulheres Negras Trabalhadoras e Intelectuais

Cibele da Silva Henriques

Ressignificando As Raças: Os Deuses Pretos e Os Demônios Brancos No Discurso Nacionalista Preto Da Nação Do Islã nos Estados Unidos Da América

Rafael Filter Santos da Silva

Feminismo Negro e a Interseccionalidade de Gênero, Raça e Classe

Eunice Lea de Moraes Lucia Isabel Conceição da Silva

A Corporeidade e a Liberdade: Mulheres Negras e a Coragem De Ser

Joyce Gonçalves Restier da Costa Souza

\section{Artigos}

Os Governos Do PT e As Agências De Rating: Os Percalços De Treze Anos De Relação

Pedro Lange Netto Machado

Apropriação Cultural: Novas Configurações das Identidades na Era da Globalização

Bárbara Lopes Heleno e Rafaella Max Reinhardt

Resenha Crítica: O Segredo como Conceito Político: a propósito de Democracia e Segredo de Norberto Bobbio

Ronaldo Tadeu de Souza 


\title{
Apropriação Cultural: Novas Configurações das Identidades na Era da
}

\section{Globalização}

Cultural Appropriation: New Configurations of Identities in the Globalization Era

\author{
Bárbara Lopes Heleno ${ }^{1}$ \\ Rafaella Max Reinhardt ${ }^{2}$
}

\section{RESUMO}

A globalização aproximou o mundo e transformou a forma dos sujeitos construírem suas identidades. Paralelamente, grupos culturais minoritários disputam a exclusividade de símbolos que são objetos definidores de sua cultura e se tornaram bens de consumo. Neste artigo, buscamos realizar uma análise teórica sobre o fenômeno da apropriação cultural enquanto uma desigual disputa de poder a partir da construção identitária dos sujeitos num mundo globalizado.

PALAVRAS-CHAVE: Apropriação Cultural; Globalização; Identidade; Representação.

\begin{abstract}
Globalization brings the world closer together and changes the way individuals construct their identities. At the same time, minority cultural groups compete for the exclusivity of symbols, which are defining objects of their culture and have become consumer goods. In this article, we seek to carry out a theoretical analysis on the phenomenon of cultural appropriation as an unequal power struggle based on the identity construction of subjects in a globalized world.
\end{abstract}

KEYWORDS: Cultural Appropriation; Globalization; Identity; Representation.

1 Pós-graduanda em Cidadania e Direitos Humanos no Contexto das Políticas Públicas, bacharel em Comunicação Social (com ênfase em Publicidade e Propaganda) e graduanda em História, todos pela PUC Minas. E-mail: barbaralopesh@gmail.com.

2 Pós-graduanda em Cidadania e Direitos Humanos no Contexto das Políticas Públicas, Bacharel em Ciências Sociais pela Pontifícia Universidade Católica de Minas Gerais. E-mail:rafaellareinhardt@gmail.com. 


\section{O CENÁRIO}

O debate sobre a apropriação cultural tem ganhado fôlego principalmente em relação a aspectos da cultura negra e indígena no Brasil. À luz dessas discussões, o presente artigo tem o objetivo de realizar uma análise teórica sobre a construção identitária num mundo globalizado, guiada pelo capitalismo que impõe padrões estéticos normatizantes, sem se preocupar com a apropriação de bens culturais, definidos por alguns grupos como símbolos de resistência.

Vale ressaltar que esse artigo não pretende realizar uma valoração dos conceitos ou um estudo de caso sobre algum movimento específico. Os tópicos aqui apresentados visam analisar o processo de construção identitária, levando em conta as características externas que influenciam o sujeito, de modo que a partir dela são gerados rótulos que classificam os sujeitos entre superiores e inferiores, sendo que estes criam um processo de resistência identitária para a permanência simbólica de suas culturas nesse processo de fluidez de identidade.

Em função da globalização, nenhuma cultura permanece intocada, e nesse processo as culturas marginalizadas precisam de um meio de não serem totalmente apagadas pelas classes dominantes, que se apropriam de símbolos conferidores de identidade grupal e os esvaziam do sentido original e histórico.

\section{REPRESENTAÇÃO E IDENTIDADE}

O conceito de representação varia de uma área de conhecimento para outra. Na maioria das vezes é abordado no campo da Filosofia e da Semiótica, em que o termo em questão é usado como sinônimo de signo.

\footnotetext{
A representação [...] é uma operação de apropriação e de invenção a partir de elementos daquilo que é representado. Para tanto, as representações recorrem e fazem referência ao conjunto dos estoques de significados cujas propriedades técnicas e estilísticas estão relacionadas a um modo particular de perceber e projetar esquemas, modelos e visões de mundo. (CORRÊA; SILVEIRA, 2014, p. 208-209).
} 
O culturalista Stuart Hall compreende a representação como o processo cultural que se utiliza da linguagem para produção de sentido. Assim, "é por meio dos significados produzidos pelas representações que damos sentido à nossa experiência e àquilo que somos" (HALL apud CORRÊA; SILVEIRA, 2014, p. 208-209). Os autores destacam que as representações têm uma característica de indecidibilidade e imprecisão, possibilitando uma diversidade de sentidos. Através desse conceito, observam que "as práticas sociais são organizadas, influenciadas e conduzidas pelas representações, com efeitos práticos e reais”. Para o filósofo Michel Foucault, (apud CORRÊA; SILVEIRA, 2014), as representações estão vinculadas à produção do saber social, sendo suas dimensões e consequências ligadas às ideias de verdade e circulação do poder.

Do ponto de vista de Vera França (apua CORRÊA, SILVEIRA, 2014, p. 213), as representações são definidas como sinônimos de signos, imagens, formas e conteúdos de pensamento. Em outras palavras, são um conjunto de ideias produzidas por um grupo ou sociedade, ou seja, tudo o que é cheio de sentido e "nos permite formar relações com a cultura e com o mundo" (FRANÇA apud CORRÊA, SILVEIRA, 2014, p. 213). Essa representação não é unidirecional, porque "são produzidas no bojo de processos sociais, espelhando diferenças e movimentos da sociedade" (FRANÇA apua CORRÊA, SILVEIRA, 2014, p. 213). Desta forma, deve ser vista como movimento de tensão e conflito, desde a sua estrutura até mecanismos internos, estando em fluxo contínuo na sociedade, materializadas em imagens, objetos, textos e práticas. Percebe-se, então, a influência da sociedade sobre as representações, que se interligam através da sociabilidade.

Assim sendo, as representações, na perspectiva de Corrêa e Silveira (2014), não são instituições ou entidades, visto que são construídas e reconstruídas conforme as relações entre pessoas e grupos, capazes de ressaltar valores comuns da sociedade em questão. Logo, essa representação coletiva (de um grupo) atua na definição de um rótulo de "valor humano inferior" (ELIAS; SCOTSON, 2000, p. 24). Esses discursos moldam sujeitos e organizam as relações sociais que estabelecem tais classificações.

O conceito de identidade também é muito importante a este estudo, porque, segundo Hall (1997), ela é formada a partir da interação com o outro, ou seja, a sociedade e eu. Neste aspecto, se faz necessário o reconhecimento desse outro para que a identidade se forme, o que estabelece um conflito, visto que a dificuldade de reconhecimento da alteridade fragiliza a construção da identidade. 
Stuart Hall (2001, p. 7) analisa as mudanças do sujeito ao longo do tempo, sendo este capaz, antes do advento da modernidade, de definir suas ações a partir de referências culturais e sociais - o que o autor denomina de "identidades velhas", as quais por muito tempo consolidaram a vida social. Por interferência da modernidade e, consequentemente, das transformações trazidas pela globalização, essas identidades se encontram enfraquecidas, fazendo surgir novas configurações identitárias que possibilitam a intervenção e interação do sujeito nesse processo de construção. Esse sujeito pós-moderno não possui uma única identidade e sim várias, visto que ela se modifica de acordo com o momento e lugar em que ele está inserido, buscando aceitação por parte do grupo e/ou comunidade a que pertence. Logo, pode-se dizer que o sujeito está fragmentado, por atribuir várias identidades (contraditórias, ou não), e isso implica uma "perda de si" ou uma "crise de identidade". Assim, esses valores são guiados por identidades regionais e têm constantes configurações em decorrência da globalização, estando submetidos cada vez mais a intervenções externas. Hall (2001) destaca que a identidade sólida deu lugar à identidade fluída (ou fragmentada), e essa identidade pessoal se tornou uma forma de manter o estilo de vida individual, escolhido por meio das roupas, acessórios, entre outros.

Giddens defende a ideia de que isso acontece "à medida que áreas diferentes do globo são postas em interconexão umas às outras, ondas de transformação social atingem virtualmente toda a superfície da terra - e a natureza das instituições modernas" (GIDDENS apud HALL, 1997, p. 16). Isso explica a mudança das formas da identidade ao longo do tempo, e afirma que a busca por uma identidade é uma questão oriunda da modernidade, e do indivíduo ocidental.

Nestor Garcia Canclini reforça essa concepção ao destacar que estamos distantes da época em que a identidade era definida a partir da essência do indivíduo, e que hoje ela é configurada por meio do "possuir", submetendo-se ao consumo e à criação da falsa necessidade de objetos que têm constantes transformações. Isso torna cada vez mais "instáveis as identidades fixadas em repertórios de bens exclusivos de uma comunidade étnica ou nacional" (CANCLINI, 1990, p. 39), como no exemplo dado pelo autor, em que os sujeitos pós-modernos têm as suas identidades ordenadas mais em torno dos filmes de Hollywood do que dos símbolos territoriais de memória da pátria. Assim, as identidades são formadas como um alvo de "repertório fragmentado de mini papéis mais do que como o núcleo de uma hipotética interioridade" (CANCLINI, 1990, p. 39), sendo construídas a partir de práticas vinculadas ao social e ao olhar do outro. 
A cada dia, novas identidades surgem em meio a essa mistura cultural em que todos estão submetidos, em virtude do mundo globalizado.

\footnotetext{
Quanto mais a vida social se torna mediada pelo mercado global de estilos, lugares e imagens, pelas viagens internacionais, pelas imagens da mídia e pelos sistemas de comunicação globalmente interligados, mais as identidades se tornam desvinculadas desalojadas - de tempos, lugares, histórias e tradições específicos e parecem "flutuar livremente”. (HALL apud FARIAS, SERTÓRIO, 2016, p. 7).
}

Com isso, alguns grupos se apropriam de um produto de determinada cultura para a construção de um reconhecimento instantâneo de uma identidade, processo que chamamos de apropriação,e será discutido mais à frente.

As identidades, então, são manipuladas e orientadas por meio das relações de poder estabelecidas pela sociedade, onde os grupos subalternos, chamados de minorias políticas, têm suas identidades marginalizadas por falta de espaço representativo, não constituindo valor para as classes dominantes.

\section{A APROPRIAÇÃO CULTURAL}

Como retratado no item anterior, as formas tradicionais de pertencimento e identidade estão em constante processo de mutação. As sociedades são cada vez menos comunidades nacionais e mais um conglomerado de diversidades. Alguns autores, como Canclini (1999), as identificam como comunidades de consumidores que compartilham gostos, modos e bens que lhes fornecem identidades comuns.

Contudo, mesmo os sentidos nacionais de unicidade foram forjados sobre uma heterogeneidade cultural, levando ao que Canclini (2011) conceitua como "hibridismo cultural"3. É importante ressaltar que na construção dessa amálgama há uma relação de desigual disputa e apropriação entre as culturas na qual "o choque da conquista desencadeou a justaposição conflitiva de conquistadores e conquistados, cujas diferenciações culturais irão desembocar tanto em ajustes ou negociações quanto na sujeição do outro". (CANCLINI, 2011, p. 72).

3 Para o autor, o hibridismo cultural remonta ao rompimento com a pureza, é a quebra entre as barreiras que separam o que é tradicional e o que é moderno, entre o culto, o popular e o que representa a cultura de massa. Consiste na miscigenação entre diferentes culturas presente no cotidiano do mundo moderno. (Canclini, 2011) 
$\mathrm{Na}$ contemporaneidade, as culturas continuam em constante tensão e em reivindicação permanente por aqueles de quem foram expropriados e marginalizados em contextos coloniais. Como fenômeno intrínseco a esse processo de disputa e dominação, símbolos são constantemente apropriados por uma cultura ou classe dominante, levando a uma "luta simbólica", como discorre Pierre Bourdieu (2007):

\begin{abstract}
As lutas, cujo pretexto consiste em tudo o que, no mundo social, se refere à crença, ao crédito e ao descrédito, à percepção e à apreciação, ao conhecimento e ao reconhecimento - nome, reputação, prestígio, honra, glória e autoridade -, em tudo que torna o poder simbólico em poder reconhecido, dizem respeito forçosamente aos detentores "distintos" e aos pretendentes "pretensiosos". Reconhecimento da distinção que se afirma no esforço para se apropriar dela, nem que fosse sob a aparência ilusória do blefe ou do símile, e para se distanciar em relação aos que estão desprovidos dela, a pretensão inspira a aquisição, por si banalizante, das propriedades até então mais distintivas, além de contribuir, por conseguinte, para apoiar continuamente a tensão do mercado dos bens simbólicos, obrigando os detentores das propriedades distintivas, ameaçadas de divulgação e vulgarização, a procurar indefinidamente a afirmação de sua raridade nas novas propriedades. (BOURDIEU, 2007, p. 235).
\end{abstract}

Como ressaltado no tópico "O cenário", o debate sobre a apropriação cultural está em voga. Este fenômeno controverso tem sido amplamente debatido fora do meio acadêmico e vem ganhando espaço nos discursos de movimentos sociais e ativistas de valorização das culturas das minorias. A polêmica que envolve a validade e aplicabilidade do conceito difere da simplicidade com que pode ser compreendido, antropologicamente, como aponta Lisandra Barbosa Macedo Pinheiro (2015), uma vez que a apropriação cultural diz respeito à adoção ou utilização de bens específicos de uma cultura - sejam eles objetos, símbolos, hábitos ou comportamentos - por pessoas e/ou grupos culturais diferentes.

Parte da pouca aceitação do conceito é proveniente de sua similaridade ao processo de assimilação de hábitos e símbolos culturais, fenômeno que faz parte das dinâmicas sociais e é intrínseco à interação entre culturas. Contudo, a complexidade da apropriação cultural se dá nas nuances de sua definição, e as questões centrais dizem menos da utilização dos símbolos e mais do esvaziamento de significados tradicionais daquele bem e a relação de dominação (colonizador/colonizado, opressor/oprimido), que permeia o "empréstimo" de símbolos entre diferentes grupos culturais.

Em uma relação dualista, enquanto historicamente houve a tentativa de supressão das tradições e cultura dos grupos minoritários, há uma fetichização, uma "atração" das classes 
dominantes pela cultura popular, valorizando aspectos estéticos em detrimento dos valores simbólicos inerentes a um determinado grupo.

\begin{abstract}
A emergência de expressões, comportamentos, vestimentas e músicas que surgem em espaços onde até pouco tempo eram desprezados é, no mínimo, vista com desconfiança pelos grupos que sempre procuraram se legitimar politicamente e buscar pelo menos a minimização das desigualdades sociais, e que mostram que sua cultura é a arma que se impunha contra a opressão e marginalidade. Por isso as críticas contra a apropriação não são somente pela apropriação cultural em si, em uma forma mais literal: não é o ato de usar turbante que ofendem esses grupos, mas o fato de usar o turbante sem ter consciência de que para muitas comunidades o significado do turbante se mostra para além da estética, possuindo um valor simbólico no âmbito da religiosidade, de crença ou de posição social dentro dessas comunidades. E mais ofensivo ainda é utilizar-se desse símbolo para fins econômicos, como mercadoria ou valor de troca, dentro da lógica capitalista de inovação de produtos, surgimento de modas ou objetos de consumo que alimentam e empoderam o referido sistema. (PINHEIRO, 2015, p. 8).
\end{abstract}

Nesse processo, culturas que foram historicamente desprezadas, começam a ter sua estética valorizada e mercantilizada pelo capital, como ressalta Canclini:

\footnotetext{
"quando selecionamos os bens e nos apropriamos deles, definimos o que consideramos publicamente valioso, bem como os modos com que nos integramos e nos distinguimos na sociedade, com que combinamos o pragmático e o aprazível". (CANCLINI, 1999, p. 45)
}

Assim, aspectos culturais que cotidianamente são relegados a uma categoria de inferioridade passam a ser símbolos de distinção entre grupos culturais dominantes, perdendo seu valor, história e significado originais, representando apenas uma demanda de consumo.

Esse fenômeno não é atual, sendo que com o objetivo de criação de uma única cultura brasileira vários símbolos culturais passaram por um processo de apropriação e "branqueamento", como o samba e a capoeira. Estes símbolos foram adotados politicamente visando marcar uma identidade nacional, entretanto a cultura nas quais eles estavam inseridos continuou relegada às classes populares e a espaços periféricos da cidade. A partir de uma trajetória de luta e reafirmação identitária das minorias, é possível observar um aumento de manifestações de movimentos de resistência e problematizações acerca desta temática.

Nessa concepção, é preciso entender que a apropriação cultural se configura como um fenômeno estrutural, fruto de um processo histórico de racismo e invisibilização cultural. Assim, quando símbolos são retirados de seu contexto e oferecidos como simples bens de consumo, é relativizada toda a luta e resistência que representam para seu grupo, o que reforça o processo de 
opressão, pois, como ressalta Giddens, "o passado é honrado e os símbolos valorizados porque contêm e perpetuam a experiência de gerações" (GIDDENS, 1991, p. 38). Apenas aquele bem emerge da condição de inferioridade, enquanto todo o arcabouço cultural que o envolve, inclusive o seu significado, continuam marginalizados.

Com o processo de globalização, esses conflitos ganham amplitude diante da complexa rede cultural mundializada que se estabelece. Uma divisão binária das culturas é excludente e parece não ser suficiente para a resolução deste conflito. A possibilidade parece residir na compreensão de que as culturas apropriadas "não se encerram em si como categorias que não dialogam com outras culturas, ou então limitadas a produtos para consumo ou apreciação, apenas" (PINHEIRO, 2015, p. 14).

\section{SOB INTERFERÊNCIA DA GLOBALIZAÇÃO}

A partir do momento em que surgiu a oportunidade de interconexão do mundo, no qual países distantes estabeleceram comunicação, foram desencadeadas profundas transformações sociais que impactaram todo o globo. Surgiram novos modos de vida a partir da interação cultural, uma vez que a globalização proporciona novas configurações e uma nova concepção de relações sócio espaciais e territoriais.

Para Canclini (1999), a globalização pode ser entendida como:

$$
\begin{aligned}
& \text { passagem das identidades modernas a outras que poderíamos chamar, embora o termo } \\
& \text { seja cada vez mais incômodo, de pós-modernas. As identidades modernas eram } \\
& \text { territoriais e quase sempre monolinguísticas. (...) as identidades pós-modernas são } \\
& \text { transterritoriais e multilinguísticas. (CANCLINI, 1999, p. 59). }
\end{aligned}
$$

Zygmunt Bauman (1998) reforça a ideia de Canclini (1999) ao dizer que a globalização é caracterizada pela falta de centralização ou por algo não determinado que origina um movimento de deslocamento da vida social e, consequentemente, as novas configurações que as identidades tiveram. Ainda nessa concepção, ele apresenta o quanto este fenômeno restabelece as limitações territoriais de certos sujeitos, e "torna extraterritoriais certos significados geradores de comunidade - ao mesmo tempo que desnuda o território, no qual outras pessoas continuam sendo confinadas, do seu significado e da sua capacidade de doar identidade" (BAUMAN, 1998, p. 16), isso porque o arranjo dos corpos no espaço físico não é essencial para "reordenar significados e relações" (BAUMAN, 1998, p. 16). 
Hall aponta algumas possíveis consequências da globalização sobre as identidades culturais, sendo elas: sua desintegração, "como resultado do crescimento da homogeneização cultural e do "pós-moderno global"' (HALL, 2006, p. 69); o reforço das identidades "locais" que “estão sendo reforçadas pela resistência à globalização" (HALL, 2006, p. 69) e, um possível declínio, em decorrência das "novas identidades - híbridas -" (HALL, 2006, p. 69) que estão tomando seu lugar. Ainda sob a perspectiva de Hall, como já dito anteriormente, a identidade está profundamente ligada ao processo de representação, assim “a moldagem e a remoldagem de relações espaço-tempo no interior de diferentes sistemas de representação têm efeitos profundos sobre a forma como as identidades são localizadas e representadas" (HALL, 2006, p. 71). As identidades globais começam a se deslocar e acabam por enfraquecer as identidades nacionais. Assim, as identidades culturais - fortes ou não - entram em declínio pela pulverização de símbolos de determinadas culturas, consequência da dependência cada vez maior dos países em consumir costumes e hábitos uns dos outros. Esse ato, segundo o autor, acaba fazendo com que as identidades sejam compartilhadas em escala mundial, de modo que quanto mais uma cultura é exposta a influências externas, menos pura ela é; logo, mais enfraquecida ela se torna. "A globalização, à medida que rompe as barreiras da distância, torna o encontro entre o centro colonial e a periferia colonizada imediato e intenso, o que ocasiona a mistura de culturas, resultando em novas" (HALL, 2006, p. 34).

Diferente das identidades culturais, Stuart Hall (2006) observa que as identidades nacionais se encontram firmes enquanto cidadania (direitos legais), mas as identidades locais e regionais são influenciadas pelas identificações "globais", que são colocadas acima da cultura nacional e, algumas vezes, acabam por suprimir as identidades nacionais.

\footnotetext{
Os fluxos culturais, entre as nações, e o consumismo global criam possibilidades de "identidades partilhadas" como "consumidores" para os mesmos bens, "clientes" para os mesmos serviços, "públicos" para as mesmas mensagens e imagens - entre pessoas que estão bastante distantes umas das outras no espaço e no tempo. A medida em que as culturas nacionais tornam-se mais expostas a influências externas, é difícil conservar as identidades culturais intactas ou impedir que elas se tornem enfraquecidas através do bombardeamento e da infiltração cultural. (HALL, 2006, p. 74).
}

Deste modo, ao alterar substancialmente o modo como as identidades se constituem, a globalização fomentou significativas transformações sociais e estruturais. Contudo, é importante frisar que a globalização não pode ser entendida como um movimento único e massificante das culturas tradicionais, como ressalta Canclini (2011), já que concomitantemente há um movimento 
"localizador", de retomada e valorização das culturas locais, que afeta e influencia o fenômeno da globalização. Deste modo, global e local não são instâncias antagônicas, mas complementares, em um fenômeno que o autor cunha como "glocal". Esse entendimento de "local" e "global" também é discutido por Hall (2006), que se atenta à influência dos mesmos na mudança das identidades. Kevin Robins observa a possibilidade de inclinação rumo à "homogeneização global", além de existir também um encantamento pela "diferença e com a mercantilização da etnia e da 'alteridade"" (ROBINS apud HALL, 2006, p. 77). Assim, junto ao impacto do "global" se tem a atração pelo "local", o que sob sua perspectiva significa que a globalização "explora a diferenciação local” (ROBINS apud HALL, 2006, p. 77) e, com isso, propõe refletir uma nova articulação entre "o global” e o "o local", "ao invés de pensar no global como substituindo o local" (ROBINS apud HALL, 2006, p. 77).

\footnotetext{
Este "local" não deve, naturalmente, ser confundido com velhas identidades, firmemente enraizadas em localidades bem delimitadas. Em vez disso, ele atua no interior da lógica da globalização. Entretanto, parece improvável que a globalização vá simplesmente destruir as identidades nacionais. E mais provável que ela vá produzir, simultaneamente, novas identificações "globais" e novas identificações "locais". (ROBINS apud HALL, 2006, p. 78).
}

Bauman cita o estudo de Michel Cozier ao abordar as estratégias da dominação, que, do ponto de vista do autor, são basicamente parecidas: "deixar a máxima liberdade de manobra ao dominante e impor ao mesmo tempo as restrições mais estritas possíveis à liberdade de decisão do dominado" (BAUMAN 1998, p. 65). Ele ainda analisa essa postura principalmente nas finanças mundiais, onde se pode observar, por exemplo, que uma possível "substituição de Estados territoriais "fracos" por algum tipo de potência legislativa e policiais globais seria prejudicial aos interesses dos 'mercados mundiais"' (BAUMAN 1998, p. 65). Cozier se atenta, então, para o estreito interesse da fragmentação política e da globalização econômica, definindoos como aliados íntimos. Bauman compartilha desse pensamento ao identificar esse processo principalmente como não acidental, em que "as quase soberanias, as divisões territoriais e a segregação de identidades promovidas e transformadas num must pela globalização dos mercados e da informação não refletem uma diversidade de parceiros iguais" (BAUMAN, 1998, p. 66).

O pesquisador John Kavanagh destaca como a globalização favoreceu os ricos, dando a eles a oportunidade da utilização das mais novas tecnologias para a movimentação (em grandes proporções) do dinheiro de forma mais eficiente, além do poder e da liberdade de ação serem estimulados pelo profundo aprimoramento da própria tecnologia. Neste cenário, segundo o 
pesquisador, os pobres não são muito influenciados, uma vez que as grandes tecnologias não interferem na vida dos mesmos. Assim, "a globalização é um paradoxo: é muito benéfica para muito poucos, mas deixa de fora ou marginaliza dois terços da população mundial" (KAVANAGH apud HALL, 1998, p. 67). Para concluir, Bauman enfatiza:

\footnotetext{
o rápido enriquecimento e o rápido empobrecimento brotam da mesma raiz, que a "imobilidade" dos miseráveis é um resultado tão legítimo das pressões "glocalizantes"4 quanto as novas liberdades dos bem-sucedidos para os quais o céu é o limite. (BAUMAN, 1998, p. 68).
}

\title{
CONSIDERAÇÕES FINAIS
}

Segundo o professor José Luiz Quadros de Magalhães ${ }^{5}$ (2017), nós, brasileiros, temos uma relação de adoração com a cultura eurocêntrica. Ao invés de valorizarmos nossa própria cultura, sempre houve uma preferência pelo importado, "de fora", especialmente pela elite branca brasileira. Este fenômeno pode ser explicado pelo colonialismo europeu no Brasil. Como ressalta Ramón Grosfoguel, “as hierarquias etnorraciais construídas por anos de subordinação colonial ficaram intactas" (GROSFOGUEL, 2012, p. 347). Neste sentido, essa desigual disputa de poder acaba por restabelecer algumas hierarquias raciais, instituídas por séculos de história colonialista.

\begin{abstract}
Em geral, são as etnias ou raças dominantes, à qual pertencem às classes e elites que controlam o poder do Estado, as que definem que cultura ou que "laço sanguíneo" será inventado como critério de pertencimento à nação, generalizável aos indivíduos submetidos ao poder do Estado. Aqueles grupos étnicos ou racializados que não nessa definição de nação são excluídos, submetidos, assimilados ou exterminados, dependendo da história particular de cada Estado-nação. Os projetos de nação da forma como historicamente têm se constituído levam em sua semente uma exclusão racista, etnocêntrica, sexista e homofóbica de um outro subordinado. (GROSFOGUEL, 2012, p. 348).
\end{abstract}

4 "Glocalização" é um termo adequado de Roland Robertson que expõe a inquebrantável unidade entre as pressões globalizantes e locais — fenômeno encoberto no conceito unilateral de globalização. (BAUMAN, 1998, p 66).

5 José Luiz Quadros de Magalhães, "Decolonialidade: alternativas para saída da crise brasileira” (palestra), Puc Minas, Belo Horizonte, 25 de outubro de 2017. 
Contudo, atualmente vivemos um cenário controverso, no qual, como salienta Pinheiro (2015), há uma fecunda discussão sobre a utilização e ressignificação de símbolos e adereços de culturas tradicionais, que, antes vistas com descaso, passaram a ser objetos de desejo e consumo por classes dominantes - "por brancos" -, esvaziando-os do seu real significado e destituindo-os de sua importância enquanto um símbolo de resistência dos grupos originários.

O que leva ao questionamento: Esse processo se desenvolveu por um reconhecimento externo da nossa riqueza cultural? Ou a partir do conhecimento das culturas internas houve uma movimentação pela valorização do popular, na tentativa de reafirmar uma "democracia racial"?

Independente da resposta para este questionamento, a discussão dos conceitos neste artigo trouxe luz para algumas questões. Foi possível compreender que o fenômeno da apropriação cultural afeta principalmente grupos historicamente subjugados e não pode ser generalizado a todos os grupos politicamente minoritários. Assim, a histórica institucionalização do poder de um grupo sobre outros, por meio da colonização e escravidão, "agiram no nível dos processos econômicos, [...] como fatores de segregação e de hierarquização social, agindo sobre as forças respectivas tanto de uns como de outros, garantindo relações de dominação e efeitos de hegemonia" (FOUCAULT, 2017, p. 152).

A conectividade permitida pela globalização influencia diretamente no padrão de escolhas identitárias dos sujeitos, e, como enfatiza Canclini (1999), muitos aspectos constituintes estão balizados em ideais de consumo, criando assim “'identidades partilhadas' - como 'consumidores' para os mesmos bens, 'clientes' para os mesmos serviços, 'públicos’ para as mesmas mensagens e imagens - entre pessoas que estão bastante distantes umas das outras no espaço e no tempo" (HALL, 2006, p. 42). Neste sentido, a discussão sobre apropriação cultural se torna mais complexa, e a ela é conferida uma flexibilidade negociada, já que ao se tornar um item de desejo o objeto ganha visibilidade, mas minimiza os simbolismos culturais por trás daquele bem.

O objetivo do presente trabalho não foi chegar a uma conclusão definitiva sobre o fenômeno da apropriação cultural, mas sim analisar o contexto em que ela surge e se manifesta. De todo modo, como ressalta Lima e Higa:

a conciliação talvez esteja na consciência, como consumidores dessa cultura, é importante [...] estabelecer uma crítica sobre todo o conteúdo que é fornecido. Principalmente aquele que não apresenta algum aprofundamento, coerência e respeito sobre outra cultura (LIMA; HIGA, 2015, s/p). 
Cadernos de Estudos Sociais e Políticos, Rio de Janeiro, vol. 7, n 13, 2017.

Submetido para avaliação em 27 de fevereiro de 2018

Aprovado para publicação em 06 de dezembro de 2018

\section{BIBLIOGRAFIA}

BAUMAN, Zigmunt. (1999), Globalização: As conseqüências humanas. Rio de Janeiro: Zahar.

BOURDIEU, Pierre (2007), A distinção: crítica social do julgamento. São Paulo: Edusp; Porto Alegre, RS: Zouk.

CANCLINI, Nestor Garcia. (1999), Consumidores e Cidadãos: conflitos multiculturais da globalização. 4. ed. Rio de Janeiro: Editora UFRJ.

Modernidade. São Paulo: EDUSP.

(2011), Culturas Hibridas: Estratégias para Entrar e Sair da

CASTELLS, Manuel. (1999), O poder da identidade. São Paulo: Paz e Terra.

COÊLHO, Tamiris; CORRÊA. Laura Guimarães. (2014), Normas e valores. In: FRANÇA, Vera Veiga; MARTINS, Bruno Guimarães; MENDES, André Melo. Grupo de Pesquisa em Imagem e Sociabilidade (GRIS): Trajetória, conceitos e pesquisa em comunicação. Belo Horizonte: PPGCom - UFMG, pp.200-207.

CORRÊA, Laura Guimarães; SILVEIRA, Fabrício José N. da. (2014), Representação. In: FRANÇA, Vera Veiga; MARTINS, Bruno Guimarães; MENDES, André Melo. Grupo de Pesquisa em Imagem e Sociabilidade (GRIS): Trajetória, conceitos e pesquisa em comunicação. Belo Horizonte: PPGCom - UFMG.

ELIAS, Norbert; SCOTSON, John L. Os estabelecidos e os outsiders: sociologia das relações de poder a partir de uma pequena comunidade. Rio de Janeiro: Zahar, 2000.

FARIAS, Helayny A. Barbosa, SERTÓRIO, Ruth G. Á. Amorim. (2016), Um diálogo entre tradição, globalização, moda e apropriação cultural. $12^{\circ}$ Colóquio de Moda - $3^{\circ}$ Congresso de Iniciação Científica em Design e Moda. Acessado em: 20/02/2018 e disponível em: http://www.coloquiomoda.com.br/anais_ant/anais/12-Coloquio-de-

Moda_2016/COMUNICACAO-ORAL/CO-03-Cultura/CO-03-Um-dialogo-entre-tradicaoglobalizacao-moda-e-apropriacao-cultural.pdf

FOUCAULT, Michel. (2015), História da Sexualidade. Vol I. A vontade de saber. Trad. Maria Thereza da Costa Albuquerque. Rio de Janeiro: Paz e Terra.

GIDDENS, Anthony. (1991), As conseqüencias da modernidade / Anthony Giddens; tradução de Raul Fiker. São Paulo: Editora UNESP. 
GROSFOGUEL, Ramón. (2012), Descolonizar as esquerdas ocidentalizadas: para além das esquerdas eurocêntricas rumo a uma esquerda transmoderna descolonial. Contemporânea - Revista de Sociologia da UFSCar. São Carlos, v. 2, n. 2, pp. 337-362. Acessado em: 20/02/2018 e disponível em: http://www.contemporanea.ufscar.br/index.php/contemporanea/article/view/86

HALL, S.. (2006; 2001;1997), A identidade cultural na pós-modernidade Tradução de Tomás Tadeu da Silva e Guaracira Lopes Louro. Rio de Janeiro: DP\&A. • (2013), Da Diáspora: Identidades e mediações Culturais. Belo Horizonte: Ed. UFMG.

LIMA, Juliana Domingos e HIGA, Felipe. (2015), Apropriação Cultural. Revista Babel. Edição Identidades. São Paulo. Acessado em: 20/02/2018 e disponível em: http://www.usp.br/cje/babel/exibir2.php?edicao_id=13\&materia_id=138

MAGALHÃES, José Luiz Quadros de. "Decolonialidade: alternativas para saída da crise brasileira" (palestra), Puc Minas, Belo Horizonte, 25 de outubro de 2017.

PINHEIRO, Lisandra Barbosa Macedo. (2015), Negritude, apropriação cultural e a "crise conceitual" das identidades na modernidade. XXVIII Simpósio nacional de História. Acessado em: 20/02/2018 e disponível em: http://www.snh2015.anpuh.org/resources/anais/39/1427821377_ARQUIVO_LISANDRATEXTOCOMPLETOANPUH2015.pdf

RONSINI, Veneza V. Mayora. (2007), Marcadores de sentido: consumo de mídia e identidades juvenis. Porto Alegre: Sulina. 